\title{
Transcriptome-wide mining suggests conglomerate of genes associated with tuberous root growth and development in Aconitum heterophyllum Wall
}

\author{
Nikhil Malhotra $^{1} \cdot$ Hemant Sood $^{1} \cdot$ Rajinder Singh Chauhan $^{1}$
}

Received: 17 April 2016/ Accepted: 28 June 2016/Published online: 11 July 2016

(c) The Author(s) 2016. This article is published with open access at Springerlink.com

\begin{abstract}
Tuberous roots of Aconitum heterophyllum constitute storage organ for secondary metabolites, however, molecular components contributing to their formation are not known. The transcriptomes of A. heterophyllum were analyzed to identify possible genes associated with tuberous root development by taking clues from genes implicated in other plant species. Out of 18 genes, eight genes encoding GDP-mannose pyrophosphorylase (GMPase), SHAGGY, Expansin, RING-box protein 1 (RBX1), SRF receptor kinase (SRF), $\beta$-amylase, ADPglucose pyrophosphorylase (AGPase) and Auxin responsive factor 2 (ARF2) showed higher transcript abundance in roots (13-171 folds) compared to shoots. Comparative expression analysis of those genes between tuberous root developmental stages showed 11-97 folds increase in transcripts in fully developed roots compared to young rootlets, thereby implying their association in biosynthesis, accumulation and storage of primary metabolites towards root biomass. Cluster analysis revealed a positive correlation with the gene expression data for different stages of tuberous root formation in A. heterophyllum. The outcome of this study can be useful in genetic improvement of $A$. heterophyllum for root biomass yield.
\end{abstract}

Electronic supplementary material The online version of this article (doi:10.1007/s13205-016-0466-y) contains supplementary material, which is available to authorized users.

Rajinder Singh Chauhan

rajinder.chauhan@juit.ac.in

1 Department of Biotechnology and Bioinformatics, Jaypee University of Information Technology, Waknaghat, Himachal Pradesh 173234, India
Keywords Aconitum heterophyllum · Biomass · Primary metabolites - Transcriptome - Transcript abundance .

Tuberous root

$\begin{array}{ll}\text { Abbreviations } \\ \text { AGPase } & \text { ADP-glucose pyrophosphorylase } \\ \text { ARF2 } & \text { Auxin responsive factor 2 } \\ \text { GMPase } & \text { GDP-mannose pyrophosphorylase } \\ \text { HOG1 } & \text { HOG1 protein kinase 1 } \\ \text { MAP K } & \text { MAP kinase } \\ \text { NOP10 } & \text { H/ACA ribonucleoprotein complex } \\ \text { PC } & \text { Plastocyanin } \\ \text { PEP C } & \text { Phosphoenolpyruvate carboxylase } \\ \text { POP } & \text { Pyruvate orthophosphate } \\ \text { RBX1 } & \text { RING-box protein 1 } \\ \text { RCA } & \text { RuBisCO activase } \\ \text { SRF } & \text { SRF receptor kinase }\end{array}$

\section{Introduction}

Aconitum heterophyllum Wall ex Royle (Ranunculaceae), popularly known as Atis, is a biennial herb native to NorthWestern and Eastern Himalayas of India. Its tuberous roots are commonly used as therapeutic ingredient in the traditional indian medicinal system for curing dyspepsia, abdominal pain, diabetes and diarrhea (Kumar et al. 2016). Non-toxic active components like atisine, hetisine and heteratisine (Pelletier et al. 1968; Malhotra et al. 2014) accumulating in tuberous roots of A. heterophyllum have wide pharmacological effects on immune, digestive and nervous systems (Rastogi and Mehrotra 1991; Sojitra et al. 2013). 
Tuberization in A. heterophyllum is a distinctive process from young rootlet to fully mature storage roots which are committed to the storage of primary as well as secondary metabolites. Several studies on morphogenesis have been carried out to understand tuberous root development in various plant species such as Ipomoea batatas and Manihot esculenta (Indira and Kurian 1977; Wang et al. 2005). Multiple genes, such as MADS-box, NAM-like and SRF have been shown to regulate tuberous root development in these plant species (You et al. 2003; Tanaka et al. 2005). The elevated expression of gene encoding AGPase enzyme in tuberous roots of $M$. esculenta has been shown to enhance biomass yield (Ihemere et al. 2006). The fundamental genetic mechanism controlling their formation in Rehmannia glutinosa has been studied to decipher the role of tuberous root development genes (Sun et al. 2010). With the advent of new technologies, a comprehensive analysis of transcriptome and proteome datasets in $R$. glutinosa provided new insight on the mechanisms for the formation of storage organ ( $\mathrm{Li}$ et al. 2015). However, the knowledge on developmental pattern of tuberous roots in A. heterophyllum is limited. The development of tuberous roots in this plant species undergoes simple, yet unique process. After seed germination, the primary roots grow immediately from the radicle and transform directly into tuberous roots rather formed into adventitious roots as in other plant species (Pal et al. 2015). Therefore, the tuberous root formation in A. heterophyllum provides a unique system to explore mechanism of sink tissue formation and development vis-à-vis accumulation of root biomass.

The tuberous roots of $A$. heterophyllum contain primary metabolites including starch and other carbohydrates besides aconites, the secondary metabolites found in the buttercup family (Ukani et al. 1996; Rana et al. 2010). Starch biosynthesis genes like AGPase and $\beta$-amylase have shown changes in expression pattern during various tuberous root developmental stages in I. batatas (Wang et al. 2006). Carbohydrate metabolism pathways were found to be activated in storage roots of Raphanus sativus (Mitsui et al. 2015). Next-generation sequencing (NGS) transcriptomes analysis of $A$. heterophyllum root and shoot tissues identified plausible candidate genes responsible for tuberous root formation and development through in silico expression profiling (Pal et al. 2015), which have been further assessed for their association with growth and developmental mechanism of tuberous roots. Fragments per kilobase of transcript per million mapped fragment (FPKM) based expression profiling study was done to identify differentially regulated genes involved in root biomass enhancement. Genes pertaining to primary metabolism in plants, such as starch production, photosynthesis, hormone metabolism and transcription factors were also studied to associate their role in storage organ development and root biomass production in A. heterophyllum.

\section{Materials and methods}

\section{Plant material}

Seeds of A. heterophyllum were germinated in the nursery of Himalayan Forest Research Institute at Shilaru, Himachal Pradesh, India (2450 $\mathrm{m}$ altitude, $31^{\circ} 23^{\prime} \mathrm{N}, 77^{\circ} 44^{\prime} \mathrm{E}$ ) under natural conditions. As the plant starts developing tuberous roots immediately after seed germination, roots of different age groups (6-36 months old) comprising young, intermediate and mature stages were harvested at same time. These were classified as R1, R2, R3, R4 and R5 for 6, $12,18,24$ and 36 months old tuberous roots, respectively (Pal et al. 2015). Plants of A. heterophyllum were also procured for collection of roots and shoots separately for gene expression analysis between both tissues. All samples were frozen immediately in liquid nitrogen and stored at $-80{ }^{\circ} \mathrm{C}$ until use.

\section{Transcriptome mining for tuberous root development genes}

Assembled NGS transcriptomes of A. heterophyllum were downloaded from the http://14.139.240.55/NGS/download. php. The transcriptome data sets corresponding to root and shoot tissues were analyzed using in-house developed scripts along with other bioinformatics approaches. The overall picture for defining parameters of tuberous root formation and development is still not clear in A. heterophyllum. Therefore, on the basis of literature survey (Table 1), genes belonging to various physicochemical processes required for tuberous root growth and biomass enhancement were mined in the transcriptomes of $A$. heterophyllum on the basis of high sequence similarity with known genes $(\geq 40 \%$ and E-value threshold of $1 \mathrm{e}-5)$. Total of 18 genes, including nine genes belonging to starch pathway (AGPase), photosynthesis (PEP C, POP, PC, RCA), hormone metabolism (HOG1, ARF2) and transcription factor (NAC1, ANT) families were selected in addition to nine genes from our previous study (Pal et al. 2015) for investigating their role in sink tissue development for biomass enhancement. Fragments per kilobase of transcript per million mapped fragment (FPKM) approach was used to calculate the transcript abundance of each gene (Pal et al. 2015, Supplementary Table 1).

\section{Genomic DNA and total RNA isolation}

Genomic DNA was isolated from leaf tissue of $A$. heterophyllum following the protocol of Murray and Thompson (1980). Total RNA from all samples was isolated using TRIzol $^{\circledR}$ Reagent (Life Technologies, USA) followed by RNase free DNase treatment (Takara Bio Inc, China) 
Table 1 Genes implicated in biomass productivity in different plant species

\begin{tabular}{|c|c|c|c|c|}
\hline Category & Sub-category & Genes & Plant species & Source \\
\hline Tuberous root formation & & $\begin{array}{l}\text { GMPase } \\
\text { SHAGGY } \\
\text { NOP10 } \\
\text { Expansin } \\
\text { Early Nod } \\
\text { RBX1 } \\
\text { MAP kinase } \\
\text { SRF }\end{array}$ & $\begin{array}{l}\text { Ipomoea batatas } \\
\text { Manihot esculenta } \\
\text { Rehmannia glutinosa }\end{array}$ & $\begin{array}{l}\text { Conklin et al. (1999), Li et al. (2001, 2012), Tanaka } \\
\text { et al. (2005), Wang et al. (2005), Dreher and } \\
\text { Callis (2007), Sun et al. (2010) }\end{array}$ \\
\hline \multirow[t]{4}{*}{ Primary metabolism } & Starch pathway & $\begin{array}{l}\text { AGPase } \\
\beta \text {-Amylase }\end{array}$ & $\begin{array}{l}\text { M. esculenta } \\
\text { I. batatas }\end{array}$ & Ihemere et al. (2006), Wang et al. (2006) \\
\hline & Photosynthesis & $\begin{array}{l}\text { PEP C } \\
\text { POP } \\
\text { PC } \\
\text { RCA }\end{array}$ & $\begin{array}{l}\text { Oryza sativa } \\
\text { Solanum tuberosum }\end{array}$ & Matsuoka et al. (2001), Häusler et al. (2001) \\
\hline & Hormonal regulation & $\begin{array}{l}\text { HOG1 } \\
\text { ARF2 }\end{array}$ & Arabidopsis thaliana & Okushima et al. (2005), Godge et al. (2008) \\
\hline & Transcription factors & $\begin{array}{l}\text { NAC1 } \\
\text { ANT }\end{array}$ & A. thaliana & Xie et al. (2000) \\
\hline
\end{tabular}

according to the manufacturer's instructions. RNA integrity was assessed in $1 \%(\mathrm{w} / \mathrm{v})$ ethidium bromide-stained agarose gel and concentration was estimated using a Nanodrop 2000 spectrophotometer (Thermo Scientific, USA).

\section{Quantitative real-time PCR (qPCR) analysis}

Primer pairs for 18 genes were designed using Primer 3 (http://bioinfo.ut.ee/primer3-0.4.0/)

(Supplementary

Table 2) and tested on genomic DNA and cDNA of $A$. heterophyllum. cDNA synthesis was done using Verso cDNA synthesis kit (Thermo Scientific, USA) from total RNA $(5 \mu \mathrm{g})$ as per manufacturer's instructions. The cDNAs were then separated by electrophoresis, stained with ethidium bromide to further verify equal concentrations (100 ng each). The reaction was performed in triplicate on a CFX96 system (Bio-Rad Laboratories, Hercules, CA, USA) with the iScript one step RT PCR kit (Bio-Rad). The PCR protocol was as follows: denaturation for $5 \mathrm{~min}$ at $94{ }^{\circ} \mathrm{C}$, followed by 40 cycles each of denaturation for $20 \mathrm{~s}$ at $94{ }^{\circ} \mathrm{C}$, annealing for $30 \mathrm{~s}$ at $48-52{ }^{\circ} \mathrm{C}$, followed by one elongation step for $20 \mathrm{~s}$ at $72{ }^{\circ} \mathrm{C}$. $26 \mathrm{~S}$ rRNA and GAPDH were used as internal controls for calculating transcript abundance. The significant differences between replicates were statistically evaluated by standard deviation in the form of error bars as mean \pm SD for data recorded in triplicates (repeated thrice).

\section{Statistical analysis}

Cluster analysis was done for gene expression profiles obtained from qPCR data with the help of $K$-means clustering, Agglomerative hierarchical clustering (AHC) and Gaussian mixture model (GMM) methods (Yu and Qin 2008; Jain 2010). Its aim was to establish correlation between abundance of the transcripts and the corresponding tuberous root developmental stages. $K$-means clustering aims to partition $N$ observations into $K$ clusters in which each observation belongs to the cluster with the nearest mean, serving as a prototype of the cluster. AHC generates dendrogram which represents a hierarchy of partitions. It is then possible to choose a partition by truncating the tree at a given level, the level depending upon user-defined constraints. Fitted GMMs cluster by assigning query data points to the multivariate normal components that maximize the component posterior probability of the given data set.

\section{Results and discussion}

\section{Expression analysis of tuberous root development genes}

To gain an insight into the molecular basis of sink organ, i.e., tuberous root development in A. heterophyllum, quantitative expression of 18 genes was studied in different 
Fig. 1 Expression status of tuberous root development genes in different tissues (roots and shoots) of A. heterophyllum. Error bars represent mean \pm SD for data recorded in triplicates (repeated thrice)

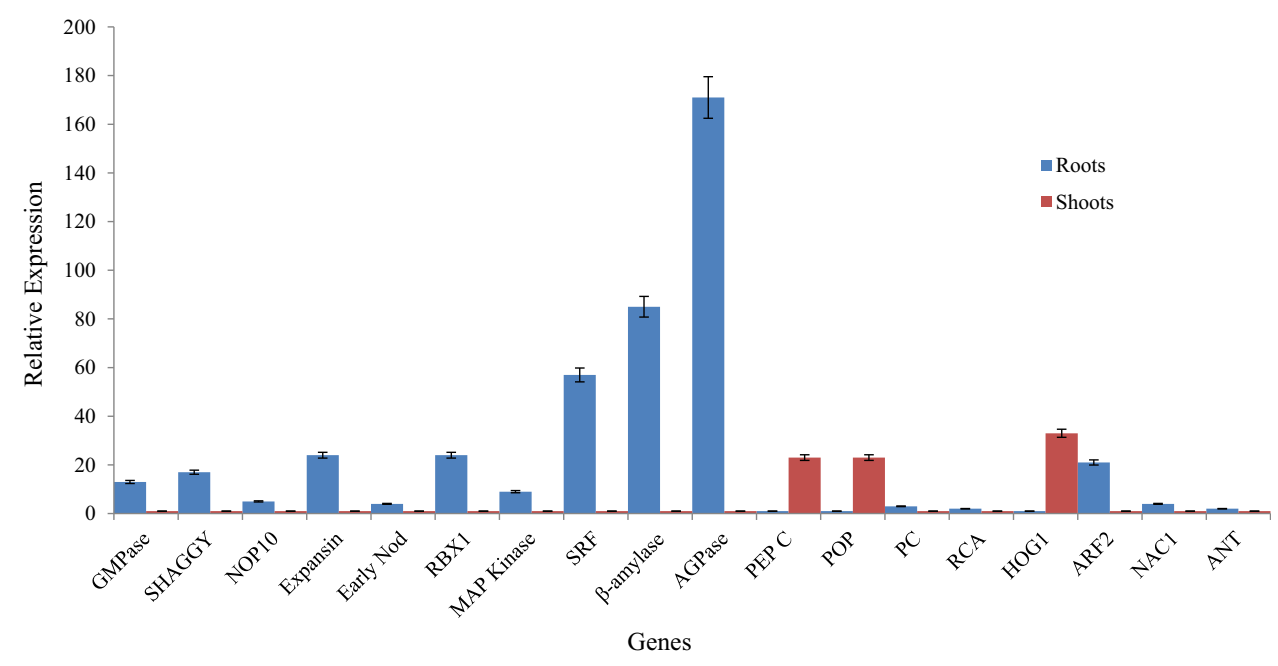

tissues using transcript abundance analysis. qPCR analysis revealed that 15 out of 18 genes of aforementioned classes had relatively higher expression in roots of $A$. heterophyllum compared to shoots. Eight genes encoding GMPase, SHAGGY, Expansin, RBX1, SRF, $\beta$-amylase, AGPase and ARF2 showed elevated level of transcripts in roots (13-171 folds) compared to shoots (Fig. 1). The transcripts of AGPase, $\beta$-amylase and SRF genes showed highest transcript abundance of 171-, 85- and 57-fold, respectively, in roots. Relatively higher expression of genes coding for AGPase and $\beta$-amylase enzymes was positively correlated to their role in starch biosynthesis in M. esculenta (Ihemere et al. 2006; Saithong et al. 2013), I. batatas (Wang et al. 2005) and model crop species like Oryza sativa and Zea mays (Geigenberger 2011). Additionally, the starch production is regulated by the activity of AGPase, the first enzyme of the starch biosynthetic pathway ( $\mathrm{Li}$ et al. 2012). The transcript of SRF gene increased 57-fold in roots compared to shoots. The gene has been found to developmentally regulate storage root formation in I. batatas by actively initiating cell division process, thereby causing thickening of tuberous roots (Tanaka et al. 2005). The higher expression of this gene has been shown to regulate plant carbohydrate metabolism in $I$. batatas (Li and Zhang 2003). The genes encoding for RBX1 and Expansin enzymes showed 24-fold transcript increase in the roots of $A$. heterophyllum. The ubiquitination activities, which are primarily active during tuberous root development, are controlled by RBX1 enzyme (Dreher and Callis 2007). Similarly, Expansin is well known regulator of cell wall extension during sink organ development in $R$. glutinosa (Sun et al. 2010). The results of this analysis were in agreement with the in silico expression profiles of nine genes reported in Pal et al. (2015).

Furthermore, three genes encoding PEP C, POP and HOG1 showed highest transcript abundance of 23-, 23- and 33-fold, respectively, in shoots of $A$. heterophyllum compared to roots which was evident as far as whole plant development is concerned. These results were comparable to the role of major pathways of primary metabolism towards plant growth and development. For example, photosynthesis genes, PEP C and POP have been shown to influence photosynthetic capacity and seed yield in $O$. sativa (Matsuoka et al. 2001). Moreover, over expression of these genes regulated cytosolic enzymatic levels of photosynthetic pathway resulting in yield enhancement of Solanum tuberosum (Häusler et al. 2001). Cytokinin production in Arabidopsis thaliana has been found to be regulated by HOG1 gene which significantly control biomass yield (Godge et al. 2008).

The relative role of 15 genes showing higher expression in roots was further validated on different developmental stages of tuberous root formation in A. heterophyllum. This was done to ascertain their significance in root biomass increase by screening all stages, from young rootlet to fully developed tuberous roots. Comparative expression analysis of tuberous root development stages (see "Materials and methods") revealed that almost all genes showed increase in transcript abundance in R4 and R5 stages compared to R1, $\mathrm{R} 2$ and R3 stages. The results showed nonsignificant changes in the expression levels of eight genes coding for GMPase, SHAGGY, NOP10, Expansin, RBX1, AGPase, $\beta$ amylase and SRF enzymes from stages R1-R3, significant increase in intermediate R4 stage (6-39 folds) and dramatic increase in their transcript levels in fully developed mature tuberous roots of R5 stage (11-97 folds) in A. heterophyllum (Fig. 2). The precise reasons for variations in transcript abundance of these genes are not clear; however, the capacity of sink organ to biosynthesize and accumulate primary metabolites have been known to increase with age of the plant. For example, carbohydrate metabolism and starch accumulation were found to increase with tuberous 
Fig. 2 Expression status of tuberous root development genes in tuberous root developmental stages (R1-R5) of A. heterophyllum. Error bars represent mean \pm SD for data recorded in triplicates (repeated thrice)

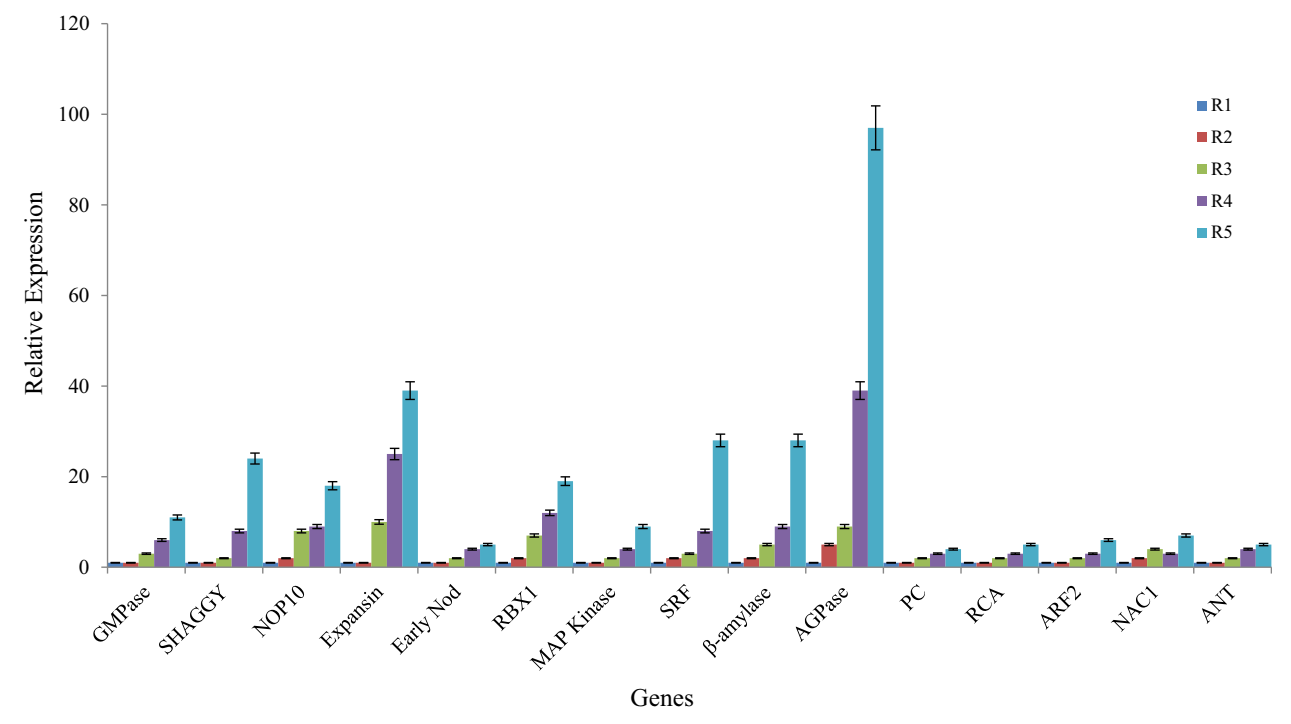

root development in $R$. sativus (Mitsui et al. 2015) and $I$. batatas (Wang et al. 2015), respectively. The transcript of AGPase gene showed 97-fold expression in R5 stage compared to R1 stage. This could be related to the formation of fully developed sink tissue with increased storage ability for the accumulation of starch and other sugars (Saithong et al. 2013). Being a rate-limiting enzyme of starch biosynthesis, the expression pattern of AGPase gene was consistent with the published reports (Yu et al. 2010). Similarly, the 28-fold increase in transcript abundance of gene coding for $\beta$ amylase enzyme corresponds to its regulatory role in starch biosynthetic pathway (Buléon et al. 1998). The expression of SRF gene showed 28-fold increase in R5 stage compared to R1 stage. Previous reports have suggested that the mature storage roots of I. batatas (Tanaka et al. 2005) accumulate carotenoids, therefore, it was observed that the expression of SRF gene increases with the formation of fully developed tuberous roots having utmost rate of primary metabolism. Interestingly, the change in expression pattern of Expansin transcript was indeed an unforeseen finding. It showed 39-fold increase in R5 stage than R1 stage while its expression remained 24-fold in roots compared to shoots. The increase in its transcript level is attributed to its involvement in various biochemical and physiological processes for tuberous root development including root hair formation for rapid cell proliferation in various plant species (Huang et al. 2001; Li et al. 2003). The transcripts coding for SHAGGY and NOP10 genes showed 24- and 18-fold increase in expression level in R5 stage compared to R1 stage. SHAGGY has been known to be involved in plant developmental processes ( $\mathrm{Li}$ et al. 2001) while NOP10 regulates mRNA splicing and ribosome biogenesis (Meier 2005), but its exact role in plant processes remains to be elucidated. Further, NAC1 and ANT are known for the biosynthesis and accumulation of primary metabolites towards biomass production in plants, but surprisingly, their transcripts did not showed significant increase in expression with increase in the root biomass. This could be attributed to their role in regulating cell proliferation and organ growth by maintaining the meristematic competence of organ cells (Xie et al. 2000; Hu et al. 2003), although molecular mechanism behind such developmental signals is largely undefined and can be fully ascertained through gene function approaches.

For complete corroboration of the current findings, the data set was subjected to statistical analysis. The study showed positive correlation with the gene expression data for different stages (R1-R5) of tuberous root development in A. heterophyllum. Clustering of the whole data set revealed close relationship between R1, R2 and R3 stages showing more or less similar expression pattern while R4 and R5 stages exhibited increase in transcript abundance as plant attained maturity. The observed profiles of eight genes viz. GMPase, SHAGGY, NOP10, Expansin, RBX1, SRF, $\beta$ amylase and AGPase were found to be distinct and well separated from each other in R5 stage compared to R4 stage. The results obtained by $K$-means clustering and agglomerative hierarchical clustering (AHC) demonstrate this scenario very well (Fig. 3). Profile plot through $K$-means clustering indicated increased profiles for R4 and R5 stages while bottom up approach for clustering in AHC clearly reflected the close proximity of R1-R3 stages. Additionally, the Gaussian mixture models (GMM) for eight genes with high expression levels have ascertained their importance in the formation of tuberous roots (Supplementary Fig. 1). Overall, multiple genes of different families exhibited an important role in tuberous root architecture for biosynthesis and storage of primary metabolites, thus paving the way towards increasing the biomass yield through genetic modification in A. heterophyllum. 

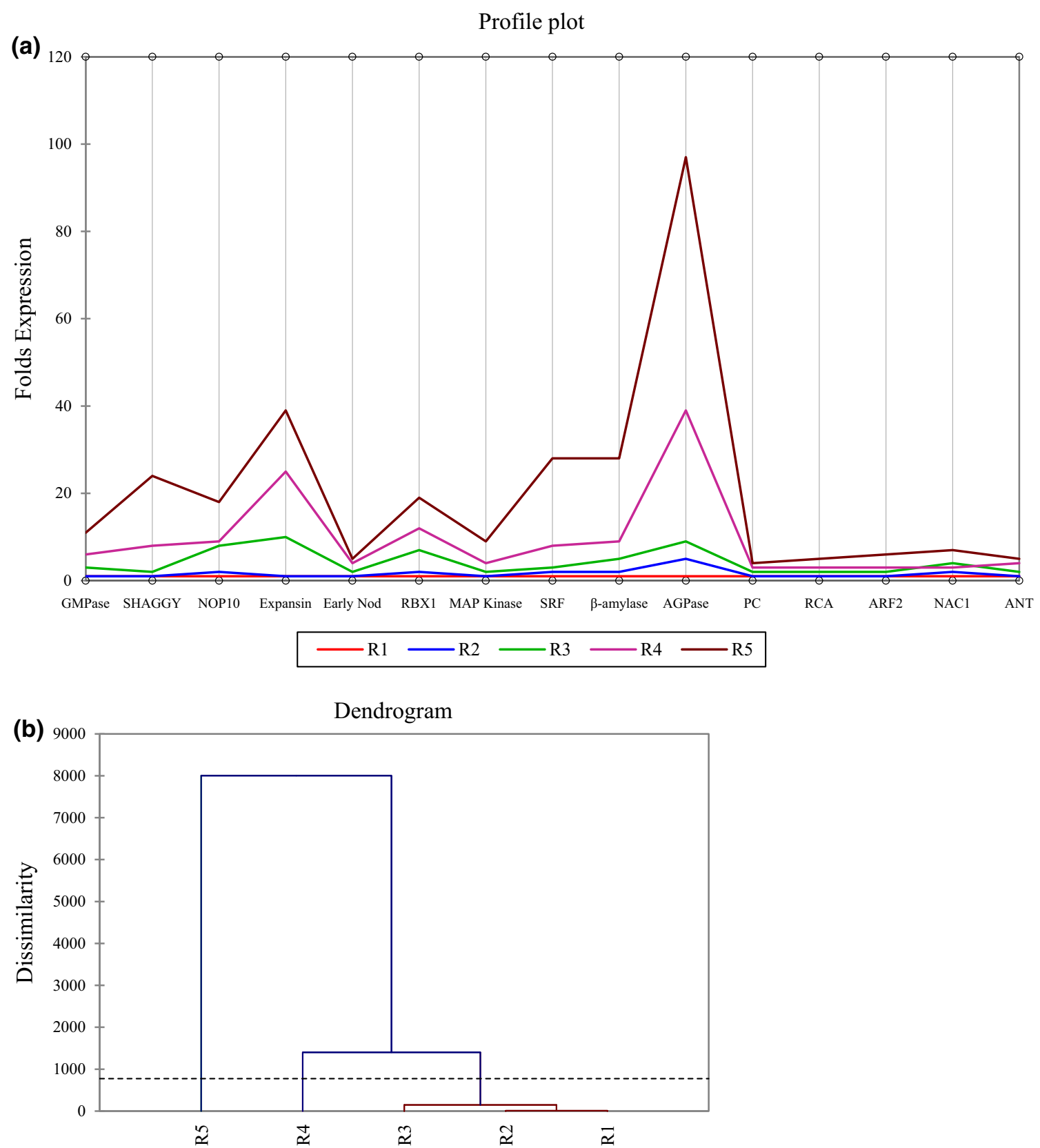

Fig. 3 Cluster analysis of tuberous root development-related genes in A. heterophyllum through a $K$-means clustering, b agglomerative hierarchical clustering. K-means clustering indicated increased profiles for R4 and R5 stages while AHC reflected close proximity between R1-R3 stages using dissimilarities. Broken line in $\mathrm{AHC}$ marks the level of truncation during clustering
In conclusion, the results obtained from this study demonstrated the apparent role of tuberous root development genes for the biomass production in A. heterophyllum. There is a possibility of altering the expression levels of key genes by gene function approaches for improving tuberous root (biomass) yield for herbal drug industries. These results can be further explored to dissect the molecular regulation of tuberous root formation and growth in A. heterophyllum.
Acknowledgments The authors are thankful to the Department of Biotechnology, Ministry of Science and Technology, Government of India, for providing funds to RSC in the form of a programme support on high-value medicinal plants. The help provided by Dr. Tiratha Raj Singh in performing statistical analysis is also acknowledged.

\section{Compliance with ethical standards}

Conflict of interest The authors declare that they have no conflict of interest. 
Open Access This article is distributed under the terms of the Creative Commons Attribution 4.0 International License (http:// creativecommons.org/licenses/by/4.0/), which permits unrestricted use, distribution, and reproduction in any medium, provided you give appropriate credit to the original author(s) and the source, provide a link to the Creative Commons license, and indicate if changes were made.

\section{References}

Buléon A, Colonna P, Planchot V, Ball S (1998) Starch granules: structure and biosynthesis. Int J Biol Macromol 23:85-112

Conklin PL, Norris SR, Wheeler GL, Williams EH, Smirnoff N, Last RL (1999) Genetic evidence for the role of GDP-mannose in plant ascorbic acid (vitamin C) biosynthesis. Proc Natl Acad Sci USA 96:4198-4203

Dreher K, Callis J (2007) Ubiquitin, hormones and biotic stress in plants. Ann Bot 99:787-822

Geigenberger P (2011) Regulation of starch biosynthesis in response to a fluctuating environment. Plant Physiol 155:1566-1577

Godge MR, Kumar D, Kumar PP (2008) Arabidopsis HOG1 gene and its petunia homolog PETCBP act as key regulators of yield parameters. Plant Cell Rep 27:1497-1507

Häusler RE, Rademacher T, Li J, Lipka V, Fischer KL, Schubert S, Kreuzaler F, Hirsch HJ (2001) Single and double overexpression of C4-cycle genes had differential effects on the pattern of endogenous enzymes, attenuation of photorespiration and on contents of UV protectants in transgenic potato and tobacco plants. J Exp Bot 52:1785-1803

Hu Y, Xie Q, Chua N-H (2003) The Arabidopsis auxin-inducible gene ARGOS controls lateral organ size. Plant Cell 15:1951-1961

Huang J, Bachem C, Jacobsen E, Visser RG (2001) Molecular analysis of differentially expressed genes during postharvest deterioration in cassava (Manihot esculenta Crantz) tuberous roots. Euphytica 120:85-93

Ihemere U, Arias-Garzon D, Lawrence S, Sayre R (2006) Genetic modification of cassava for enhanced starch production. Plant Biotechnol J 4:453-465

Indira P, Kurian T (1977) A study on the comparative anatomical changes undergoing tuberization in the roots of cassava and sweet potato. J Root Crops 3:29-32

Jain AK (2010) Data clustering: 50 years beyond K-means. Pattern Recognit Lett 31:651-666

Kumar V, Malhotra N, Pal T, Chauhan RS (2016) Molecular dissection of pathway components unravel atisine biosynthesis in a non-toxic Aconitum species, A. heterophyllum Wall. 3. Biotech 6:106

Li XQ, Zhang D (2003) Gene expression activity and pathway selection for sucrose metabolism in developing storage root of sweet potato. Plant Cell Physiol 44:630-636

Li J, Nam KH, Vafeados D, Chory J (2001) BIN2, a new brassinosteroid insensitive locus in Arabidopsis. Plant Physiol 127:14-22

Li Y, Jones L, McQueen-Mason S (2003) Expansins and cell growth. Curr Opin Plant Biol 6:603-610

Li C, Li QG, Dunwell JM, Zhang YM (2012) Divergent evolutionary pattern of starch biosynthetic pathway genes in grasses and dicots. Mol Biol Evol 29:3227-3236

Li M, Yang Y, Li X, Gu L, Wang F, Feng F, Tian Y, Wang F, Wang $X$, Lin W, Chen X, Zhang Z (2015) Analysis of integrated multiple 'omics' datasets reveals the initiation and determination mechanisms of tuberous root formation in R. glutinosa. J Exp Bot. doi:10.1093/jxb/erv288
Malhotra N, Kumar V, Sood H, Singh TR, Chauhan RS (2014) Multiple genes of mevalonate and non-mevalonate pathways contribute to high aconites content in an endangered medicinal herb, Aconitum heterophyllum Wall. Phytochemistry 108:26-34

Matsuoka M, Furbank RT, Fukayama H, Miyao M (2001) Molecular engineering of $\mathrm{C} 4$ photosynthesis. Annu Rev Plant Physiol Plant Mol Biol 52:297-314

Meier UT (2005) The many facets of H/ACA ribonucleoproteins. Chromosoma 114:1-14

Mitsui Y, Shimomura M, Komatsu K, Namiki N, Shibata-Hatta M, Imai M, Katayose Y, Mukai Y, Kanamori H, Kurita K, Kagami T, Wakatsuki A, Ohyanagi H, Ikawa H, Minaka N, Nakagawa K, Shiwa Y, Sasaki T (2015) The radish genome and comprehensive gene expression profile of tuberous root formation and development. Sci Rep 5:10835

Murray MG, Thompson WF (1980) Rapid isolation of high molecular weight plant DNA. Nucleic Acids Res 8:4321-4326

Okushima Y, Overvoorde PJ, Arima K, Alonso JM, Chan A, Chang C, Ecker JR, Hughes B, Lui A, Nguyen D, Onodera C, Quach H, Smith A, Yu G, Theologis A (2005) Functional genomic analysis of the AUXIN RESPONSE FACTOR gene family members in Arabidopsis thaliana: unique and overlapping functions of ARF7 and ARF19. Plant Cell 17:444-462

Pal T, Malhotra N, Chanumolu SK, Chauhan RS (2015) Nextgeneration sequencing (NGS) transcriptomes reveal association of multiple genes and pathways contributing to secondary metabolites accumulation in tuberous roots of Aconitum heterophyllum Wall. Planta 242:239-258

Pelletier SW, Aneja R, Gopinath KW (1968) The Alkaloids of Aconitum heterophyllum Wall: isolation and characterization. Phytochemistry 7:625-635

Rana CS, Sharma A, Kumar N, Dangwal LR, Tiwari JK (2010) Ethnopharmacology of some important medicinal plants of Nanda Devi National Park (NDNP) Uttarakhand, India. Nat Sci 8:9-14

Rastogi R, Mehrotra BN (1991) Compendium of Indian medicinal plants, vol 2. Central Drug Research Institute and National Institute of Science Communication, Lucknow, New Delhi

Saithong T, Rongsirikul O, Kalapanulak S, Chiewchankaset P, Siriwat W, Netrphan S, Suksangpanomrung M, Meechai A, Cheevadhanarak S (2013) Starch biosynthesis in cassava: a genome-based pathway reconstruction and its exploitation in data integration. BMC Syst Biol 7:75

Sojitra J, Dave P, Pandya K, Parikh V, Patel P, Patel G (2013) Standardization study of poly herbal formulation-Caspa Drops. Int J Pharm Sci Drug Res 5:113-119

Sun P, Guo Y, Qi J, Zhou L, Li X (2010) Isolation and expression analysis of tuberous root development related genes in Rehmannia glutinosa. Mol Biol Rep 37:1069-1079

Tanaka M, Takahata Y, Nakatani M (2005) Analysis of genes developmentally regulated during storage root formation of sweet potato. J Plant Physiol 162:91-102

Ukani MD, Mehta NK, Nanavati DD (1996) Aconitum heterophyllum (Ativisha) in Ayurveda. Anc Sci Life 16:166-171

Wang QM, Zhang LM, Wang ZL (2005) Formation and thickening of tuberous roots in relation to the endogenous hormone concentrations in sweetpotato. Scientia Agricultura Sinica 38:2414-2420

Wang SJ, Chen MH, Yeh KW, Tsai CY (2006) Changes in carbohydrate content and gene expression during tuberous root development of sweet potato. J Plant Biochem Biotechnol 15:21-25

Wang Z, Fang B, Chen X, Liao M, Chen J, Zhang X, Huang L, Luo Z, Yao Z, Li Y (2015) Temporal patterns of gene expression associated with tuberous root formation and development in sweetpotato (Ipomoea batatas). BMC Plant Biol 15:180 
Xie Q, Frugis G, Colgan D, Chua NH (2000) Arabidopsis NAC1 transduces auxin signal downstream of TIR1 to promote lateral root development. Genes Dev 14:3024-3036

You MK, Hur CG, Ahn YS, Suh MC, Jeong BC, Shin JS, Bae JM (2003) Identification of genes possibly related to storage root induction in sweet potato. FEBS Lett 536:101-105
Yu J, Qin SJ (2008) Multimode process monitoring with Bayesian inference-based finite Gaussian mixture models. AIChE J 54:1811-1829

Yu G, Olsen KM, Schaal BA (2010) Molecular evolution of the endosperm starch synthesis pathway genes in rice (Oryza sativa L.) and its wild ancestor, O. rufipogon L. Mol Biol Evol 28:659-671 